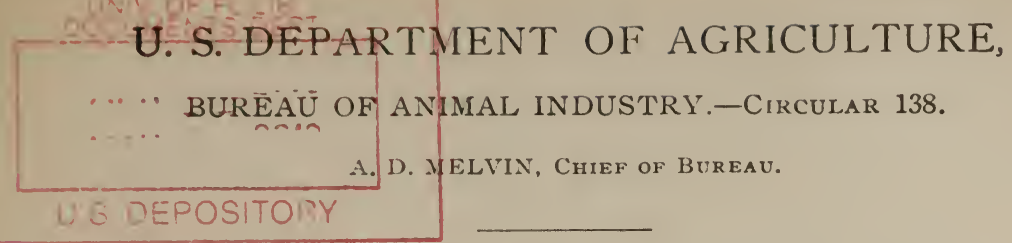

\title{
INFECTIOUS ANEMIA OR SWAMP FEVER OF HORSES.
}

\author{
By- Johix R. Mohler, V. M. D., \\ Chief of the Pathological Division.
}

Infectious anemia of horses, known also by a number of other names, as swamp fever, American surra, malarial fever, typhoid fever of horses, the unknown disease, no-name disease, plains paralysis, and pernicious anemia, has recently been the subject of much investigation. The cause of the disease has now been definitely determined as an invisible virus, which is capable of passing through the pores of the finest porcelain filters, like the infection of foot-and-mouth disease, rinderpest, hog cholera, and similar diseases. The disease is most prevalent in low lying and badly drained sections of the country, although it has been found in altitudes as high as 7,500 feet on marshy pastures during wet seasons. Therefore proper drainage of infected pastures is indicated as a preventive. It is also more prevalent during wet years than in dry seasons. It usually makes its appearance in June, and increases in frequency until October, although the chronic cases may be seen in the winter, having been contracted during the warm season.

\section{CACSE OF THE DISEASE.}

It has been conclusively proven that infectious anemia is produced by an invisible, filterable organism which is transmissible to horses, mules, and asses by subcutaneous inoculation of blood serum. The virus which is present in the blood may be transmitted to a number of equines in a series of inoculations by injecting either the whole blood, the defibrinated blood, or the blood serum which has been passed through a fine Pasteur filter, thus eliminating all the visible forms of organismal life, including bacteria, trypanosoma, piroplasma, etc. This virus has also been found to be active in the carcass of an affected animal twenty-four hours after death.

Following the injection of the infectious principle there is a period of incubation which may extend from ten days to one and one-half months, at the end of which time the onset of the disease is manifested by a rise of temperature. If uncomplicated, the infection runs a chronic course, terminating in death in from two months to one 
and one-half years, or even longer. The probability of the virus being spread by an intermediate host, such as flies. mosquitoes, internal parasites, etc., is now receiving careful investigation.

From experiments already conducted it appears that this disease, formerly supposed to be confined to Manitoba and Minnesota, is more or less prevalent in Kansas, Nebraska, Colorado, Wyoming, Montana, North Dakota, and Texas. It also occurs in Europe, having been reported in Germany under the name of infectious anemia and in France as infectious typho-anemia:

\section{SYMPTOMS.}

The disease is characterized by a progressive pernicious anemia, remittent fever, polyuria, and gradual emaciation in spite of a vora(cious appetite. It begins to manifest itself by a dull, listless appearance and by general weakness, the animal tiring very easily. This stage is followed closely by a staggering, swaying, uncertain gait, the hind legs being mostly affected. There is also noted a weakness and tenderness in the region of the loins, and at the same time the pulse increases in rapidity and may run as high as 70 , though weak, stringy, and intermittent. The temperature may rise to $103^{\circ} \mathrm{F}$. or higher, remaining high for several days, and then dropping, to rise again at irregular intervals. Toward the end of the disease the temperature oc'asionally remains persistently high. The horse may improve for a time, but usually this temporary improvement is followed by a more severe attack than the first. Venous regurgitation is sometimes noticed in the jugular before death. The quantity of urine passed is enormous in some cases. Death finally occurs from exhaustion or syncope.

The blood shows a slight decrease in the number of white blood cells, while there is a gradual but marked diminution of red corpuscles, the count running as low as $2,000,000$ per cubic millimeter, the normal count being $7.000,000$. If the blood is drawn from such an animal the resulting red clot will be about one-fifth of the amount drawn. Occasionally a slow dripping of blood-tinged serum from the nostrils is observed as a result of this very thin blood oozing from the mucous membranes. Petechir, or small hemorrhagic points. are sometimes noticed on the nictitating membrane and conjunctiva of the eye, while paleness of the visible mucous membranes of the nose and mouth is usually in evidence, although they may have a yellow or mahogany tinge. Often a fluctuating. pendulous swelling may appear on the lower lip. point of elbow, sheath, legs, under the belly, or on some other pendant portion, especially late in the disease. which is indicative of poor circulation, thinning of the blood, and consequent loss of capillary action.

[CIr. 13s] 
LESIONS.

After death the carcass is found to be very emanciated and anemic, the visible mucosa being very pale. This marked absence of adipose tissue makes the skinning of the animal a difficult task. Subcutaneous and intermuscular edema and hemorrhages are frequently observed, although it is remarkable in many cases to see how few macroscopic lesions may be present. The predominating and most constant lesion is probably the petechix so often observed in the muscle or on the serous membranes of the heart. The heart is generally enlarged and may be the only organ to show evidence of disease. In other cases the lungs may be studded with petechir, with a serous exudate present in the thoracic cavity. In addition to the petechiæ already noted, the pericardial sac generally contains an increased amount of fluid. The abdominal cavity may show peritonitis and a hemorrhagic condition of the intestines, which probably result from overfeeding in consequence of the ravenous appetite. The liver sometimes presents a few areas of degeneration, although usually normal. The spleen is at times found to be enlarged and covered with petechiæ. The kidneys may appear normal or anemic and flaccid, but microscopically they usually show a chronic parenchymatous degeneration. The lymph glands may be enlarged and hemorrhagic.

DIAGNOSIS.

The diagnosis of the disease is not difficult, especially in advanced stages. The insidious onset, remittent fever, progressive emaciation and anemia, unimpaired or ravenous appetite, staggering gait, and polyuria are a train of symptoms which make the disease sufficiently characteristic to differentiate it from other diseases affecting horses in this country. The peculiar relapsing type of fever, the great reduction in the number of red blood cells, and the absence of eosinophilia are sufficient to differentiate it from the anemias produced by internal parasites, while it may be readily distinguished from surra by the nonsusceptibility of cattle and by the great ease with which the trypanosoma may be found in the latter affection.

PROGNOSIS.

The prognosis of the disease is very unfavorable. Veterinarians in different sections of the country where it is prevalent report a mortality of 75 per cent or even higher. Recovery takes place only when treatment is begun early or when the animal has a long convalescent period.

\section{TREATMENT.}

The treatment of the disease has so far been far from satisfactory. The iodid, permanganate, and carbonate of potash have been used. Arsenic, axytol, quinin, and silver preparations have been suggested,

[Cir. 138 ] 
but all have uniformly been without success. Intestinal antiseptics have been resorted to and the results are encouraging but not altogether satisfactory. Symptomatic treatment seems to be the most dependable. For instance, Davison of this Bureau was able to reduce greatly the mortality from this affection by giving an antipyretio of 40 grains of quinin, 2 drams of acetanilid, and 30 grains of powdered nux vomica four times daily. In the late stages with weak heart action alcohol should be substituted for acetanilid. Cold-water -ponge baths may be given, and in addition frequent copious injeclions of cold water per rectum, which has a beneficial effect in relucing the temperature and in stimulating peristalsis of the bowels. which, as a result of the disease, show a tendency to become torpid during the fever. Avoid giving purgatives mnless absolutely necessary, on account of their debilitating effect, but instead give laxative, easily digestible feeds. Not infrequently a dirty yellowish tinge of the visible mucous membranes has been observed, in which cases 20 grains of calomel in from 2 to + drams of aloes in a ball or 2 -dram doses of fluid extract of podophyllin may be given. Following the subsidence of the fever a tonic should be administered composed of the following drugs in combination:

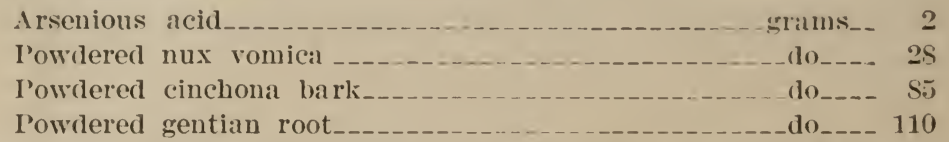

'These should be well mixed and one-half tablespoonful given at each feed to the affected animal.

As in the case of all other infectious diseases, the healthy should be separated from the sick horses, and thorough disinfection of the infected stable, stalls, litter, and stable utensils should be carried out in order to prevent the recurrence of the disease. As a disinfectant the compound solution of cresol, carbolic acid, or chlorid of lime may be used by mixing 6 ounces of any one of these chemicals with 1 gallon of water. One of the approved coal-tar sheep dips might also be used to adrantage in a 5 per cent solution (6 ounces of dip to 1 grallon of water). The disinfectant solution should be applied liberally to all parts of the stable, and sufficient lime may be added to the solution to make the disinfected area conspicuous.

Investigations are now in progress with a view of producing a vaccine or selum that will protect horses which have been exposed to the dicease.

Approved :

James Winson,

Serretury of Agriculture.

Wasmington, D. C., Jamuary 29, 1909.

[CIr, 1::S] 